\title{
Performance Comparison of Three Hybridization Categories to Solve Multi-objective Flow Shop Scheduling Problem
}

\author{
A Case Study from the Automotive Industry \\ Jebari Hakim $^{1}$, Siham Rekiek ${ }^{2}$, Rahali El Azzouzi Saida ${ }^{3}$, Samadi Hassan ${ }^{4}$ \\ Department of Information and Communication Systems \\ National School of Applied Sciences, University Abdelmalek Essaâdi \\ Tangier, Morocco
}

\begin{abstract}
The industries must preserve a rate of constant productivity; however, weaknesses appear at the level of production system which engenders high manufacturing costs. Scheduling is considered the most significant issue in the production system, the solution to that problem need complex methods to solve it. The goal of this paper is to establish three hybridization categories of the evolutionary methods $\mathrm{ABC}$ and PSO to solve multi-objective flow shop scheduling problem: Synchronous parallel hybridization using the weighted sum method of the fitness function, sequential hybridization using or not using the weighted sum method of the fitness function, and asynchronous parallel hybridization using the weighted sum method of the fitness function, then to test these methods in an automotive multi-objective flow shop and to perform an in-depth comparison for verifying how the multi hybridization and the hybridization categories influence the resolution of multiobjective flow shop scheduling problems. The results are consistent with other studies that have shown that the multi hybridization improves the effectiveness of the algorithm.
\end{abstract}

Keywords-Scheduling; multi-objective; flow shop; multi hybridization; artificial bee colony $A B C$; particle swarm optimization PSO

\section{INTRODUCTION}

The objectives of companies are diversified and the scheduling became multi-criterion. The scheduling objective are related to the time or the resources or the cost.

The scheduling problem in the production system is a accomplishment of a tasks group by taking in consideration some constraints.

The hybrid metaheuristics are proposed by Talbi [1] and are classified in three classification [2]:

- Synchronous parallel hybridization consists of incorporating an approach in an operator of another approach.

- Sequential hybridization is composed by various approaches, the solution of the first approach is an initialization of the next approach.
- Asynchronous parallel hybridization, the hybrid approaches share data throughout the search process.

In the flow shop scheduling problem, every machine can make only a single operation simultaneously and every job can have just a single operation in progress at the same instant. The capacity of storage inter-machines is defined and the preemption of operations is not approved.

Solving multi-objective flow shop scheduling problem has been gaining importance in recent years, in fact, many authors have developed diverse hybrid approaches and not hybrid approaches : Genetic local search [3], artificial neural network [4], particle swarm optimization [5], ant colony system [6], GRASP heuristic [7], hybrid TP+PLS [8], pareto approach [9], [10], [11], [12], multi-objective genetic algorithm and subpopulation genetic algorithm-II and non-dominated sorting genetic algorithm-II [13], multi-objective genetic algorithm [14], quantum differential evolutionary algorithm [15], Parallel multiple reference point approach [16], glowworm swarm optimization [17], genetic algorithm [18], genetic algorithm optimization technique [19], memetic algorithm [20], hybrid non-dominated sorting genetic algorithm with variable local search [21], hybrid harmony search [22], Heuristic algorithms [23], lower-bound-based GA [24]. The author in [25] summarizes some contributions to solve flow shop scheduling problem.

However, to the authors' knowledge, very few publications are available in the literature that performed an in-depth comparison for verifying how the multi hybridization and the hybridization categories influence the resolution of multiobjective flow shop scheduling problem.

The objective of this paper is as follows:

- To establish three hybridization categories of the evolutionary methods ABC and PSO to solve multiobjective flow shop scheduling problem: Synchronous parallel hybridization using the weighted sum method of the fitness function, sequential hybridization using or not using the weighted sum method of the fitness function, and asynchronous parallel hybridization using the weighted sum method of the fitness function.

*corresponding Author 
- To make tests of these methods in an automotive multiobjective flow shop.

- To perform an in-depth comparison for verifying how the multi hybridization and the hybridization categories influence the resolution of multi-objective flow shop scheduling problems.

The rest of the paper is organized as follows: the fundamentals of ABC and PSO will be explained in Section 2. In Section 3, the authors described the implementation of the proposed methods. The results and discussion are explained in Section 4. In Section 5, the conclusion and perspectives for further research are presented.

\section{THE MATERIAL AND METHOD}

\section{A. Fundamentals of Artificial Bee Colony Algorithm}

The artificial bee colony $\mathrm{ABC}$ algorithm is one of the most newly added swarm-based algorithms. ABC method created by Karaboga, it was copied the intelligent foraging behavior observed in the domestic bees to take the process of foraging [26].

$\mathrm{ABC}$ technique was produced for optimization problems in the continuous field. Recently, it was further enlarged for optimization problems in the discrete area [27] [28] [29] [30] [31].

A complete review of the utilization of $\mathrm{ABC}$ algorithm can be found in [32].

Four phases make ABC: Initialization bee phase, employed bees phase associate with particular food sources, onlooker bees phase look at the dance of engaged bees within the hive to choose a food source, and scout bees phase search randomly food sources.

In the $\mathrm{ABC}$ algorithm, the position of a food source corresponds to a possible feasible solution to the studied problem, and the nectar amount of a food source design the fitness of the solution.

The ABC algorithm merges techniques of local search and global search, trying to balance between the exploration and the exploitation of the search zone.

The main steps of the ABC method are as follows:

Initialization Phase (Initialize Population)

REPEAT

Employed Bees Phase (Put the employed bees on their food sources)

Onlooker Bees Phase (Put the onlooker bees on the food sources according to their nectar amounts)

Scout Bees Phase (Send the scouts to the search zone for exploring new food sources)

Record the best food source attained so far

UNTIL requirements are met

\section{B. Fundamentals of Particle Swarm Optimization}

Particle Swarm Optimization PSO technique is a popular swarm-intelligence-based algorithm that optimizes a problem using an approach that is motivated by the movements of schooling of fishes or a flock of birds.

It was founded by Eberhart and Kennedy in 1995 [33] and has received significant attention from researchers studying in several research fields and has been successfully employed to many optimization problems since then [34] [35] [36].

The candidate solutions of a studied problem are designed as particles that form a population. The location of each particle is determined with two swarm main characteristics: the particle's position and velocity. The position of a particle represents a specific solution to the studied problem, while velocity is employed to define the direction of the particle in the next iteration.

Two reference values manage the movement of a particle throughout the iterations: The best fitness value obtained by the particle and the best fitness value of the swarm registered so far. The PSO has a memory that deposits the best fitness value of all particles achieved so far, and the corresponding position.

Applying these principles, improvement is accomplished and the PSO is conducted to the optimal solution.

The main steps of PSO are as follows:

Randomly generate the initial population and the velocities

Repeat

Determine the best values of particles in the swarm

Change the best particles in the swarm

Determine the best particle

Update the velocities of particles

Update the particle position

Until requirements are met

\section{The Proposed Methods}

The ABC has a high capacity to explore the global optimum who it is not immediately employed, because the ABC stocks it at each iteration, on the other hand, the PSO can immediately employ the global best solution at iteration.

To obtain a better-performing method that exploits and combines advantages of these algorithms, the proposed hybridization between the ABC and PSO is applied.

The proposed hybrid metaheuristics are developed in threehybridization categories: Synchronous parallel hybridization, sequential hybridization and asynchronous parallel hybridization.

1) Synchronous parallel multiple hybridization of $A B C$ with PSO: The authors developed a new approach of synchronous parallel hybridization of ABC and PSO called HABCPSO. This approach consists to employ in the employed bees phase or/and in the onlooker bees phase or/and in the scout bees phase, the position and the velocity updating process, the Table I shown the configuration of the HABCPSO methods.

Consequently, the procedure of $\mathrm{HABCPSO} 2$ and HABCPSO3 can be found in Fig. 1 and Fig. 2, respectively. 
The fitness function $F$ minimized in HABCPSO corresponds to the balanced sum of both objectives functions $F 1$ and F2, with weights $\beta 1$ and $\beta 2$ defined as follows:

$\mathrm{F}=\mathrm{F}_{1} \beta_{1}+\mathrm{F}_{2} \beta_{2}, \beta_{1}+\beta_{2}=1, \beta_{1}>0, \beta_{2}>0$

1) Sequential hybridization of $A B C$ with PSO: The proposed hybrid methods, denoted as $[\mathrm{ABC}+\mathrm{PSO}](\mathrm{F})$ and $\mathrm{ABC}(\mathrm{F} 1)+\mathrm{PSO}(\mathrm{F} 2)$, are founded on the recombination of two procedures $\mathrm{ABC}$ and PSO. The PSO is applied after the $\mathrm{ABC}$.

PSO has used the output of the previous as its inputs, there are acting in a pipeline way.

The procedures of $[\mathrm{ABC}+\mathrm{PSO}](\mathrm{F})$ and $\mathrm{ABC}(\mathrm{F} 1)+\mathrm{PSO}(\mathrm{F} 2)$ are illustrated in Fig. 3.

The fitness function $\mathrm{F}$ minimized in $[\mathrm{ABC}+\mathrm{PSO}](\mathrm{F})$ corresponds to the balanced sum of both objectives functions F1 and F2, with weights $\beta 1$ and $B 2$ defined by the function 1 .

The fitness functions $\mathrm{F} 1 / \mathrm{F} 2$ minimized in $\mathrm{ABC}(\mathrm{F} 1)+\mathrm{PSO}(\mathrm{F} 2)$ corresponds to objective function $\mathrm{F} 1$ minimized in $\mathrm{ABC}(\mathrm{F} 1)$ and objective function $\mathrm{F} 2$ minimized in PSO(F2).

2) Sequential hybridization of PSO with $A B C$ : The proposed hybrid methods denoted as $[\mathrm{PSO}+\mathrm{ABC}](\mathrm{F})$ and $\mathrm{PSO}(\mathrm{F} 1)+\mathrm{ABC}(\mathrm{F} 2)$ are founded on the recombination of two procedures $\mathrm{ABC}$ and PSO. The $\mathrm{ABC}$ is applied after the PSO.

$\mathrm{ABC}$ has used the output of the previous as its inputs, there are acting in a pipeline way.

The procedures of $[\mathrm{PSO}+\mathrm{ABC}](\mathrm{F})$ and $\mathrm{PSO}(\mathrm{F} 1)+\mathrm{ABC}(\mathrm{F} 2)$ are illustrated in Fig. 4.

TABLE I. The CONFIGURATION OF THE HABCPSO METHODS

\begin{tabular}{|c|c|c|c|}
\hline & ABC & & \\
\hline $\begin{array}{l}\text { Hybrid ABC } \\
+ \text { PSO }\end{array}$ & $\begin{array}{l}\text { Employed bee } \\
\text { phase }\end{array}$ & $\begin{array}{l}\text { Onlooker bee } \\
\text { phase }\end{array}$ & Scout bee phase \\
\hline HABCPSO1 & $\begin{array}{l}\text { position and } \\
\text { velocity updation } \\
\text { process }\end{array}$ & & \\
\hline HABCPSO2 & $\begin{array}{l}\text { position and } \\
\text { velocity updation } \\
\text { process }\end{array}$ & $\begin{array}{l}\text { position and } \\
\text { velocity updation } \\
\text { process }\end{array}$ & \\
\hline HABCPSO3 & $\begin{array}{l}\text { position and } \\
\text { velocity updation } \\
\text { process }\end{array}$ & $\begin{array}{l}\text { position and } \\
\text { velocity updation } \\
\text { process }\end{array}$ & $\begin{array}{l}\text { position and } \\
\text { velocity updation } \\
\text { process }\end{array}$ \\
\hline HABCPSO4 & & $\begin{array}{l}\text { position and } \\
\text { velocity updation } \\
\text { process }\end{array}$ & \\
\hline HABCPSO5 & & $\begin{array}{l}\text { position and } \\
\text { velocity updation } \\
\text { process }\end{array}$ & $\begin{array}{l}\text { position and } \\
\text { velocity updation } \\
\text { process }\end{array}$ \\
\hline HABCPSO6 & $\begin{array}{l}\text { position and } \\
\text { velocity updation } \\
\text { process }\end{array}$ & & $\begin{array}{l}\text { position and } \\
\text { velocity updation } \\
\text { process }\end{array}$ \\
\hline HABCPSO7 & & & $\begin{array}{l}\text { position and } \\
\text { velocity updation } \\
\text { process }\end{array}$ \\
\hline
\end{tabular}

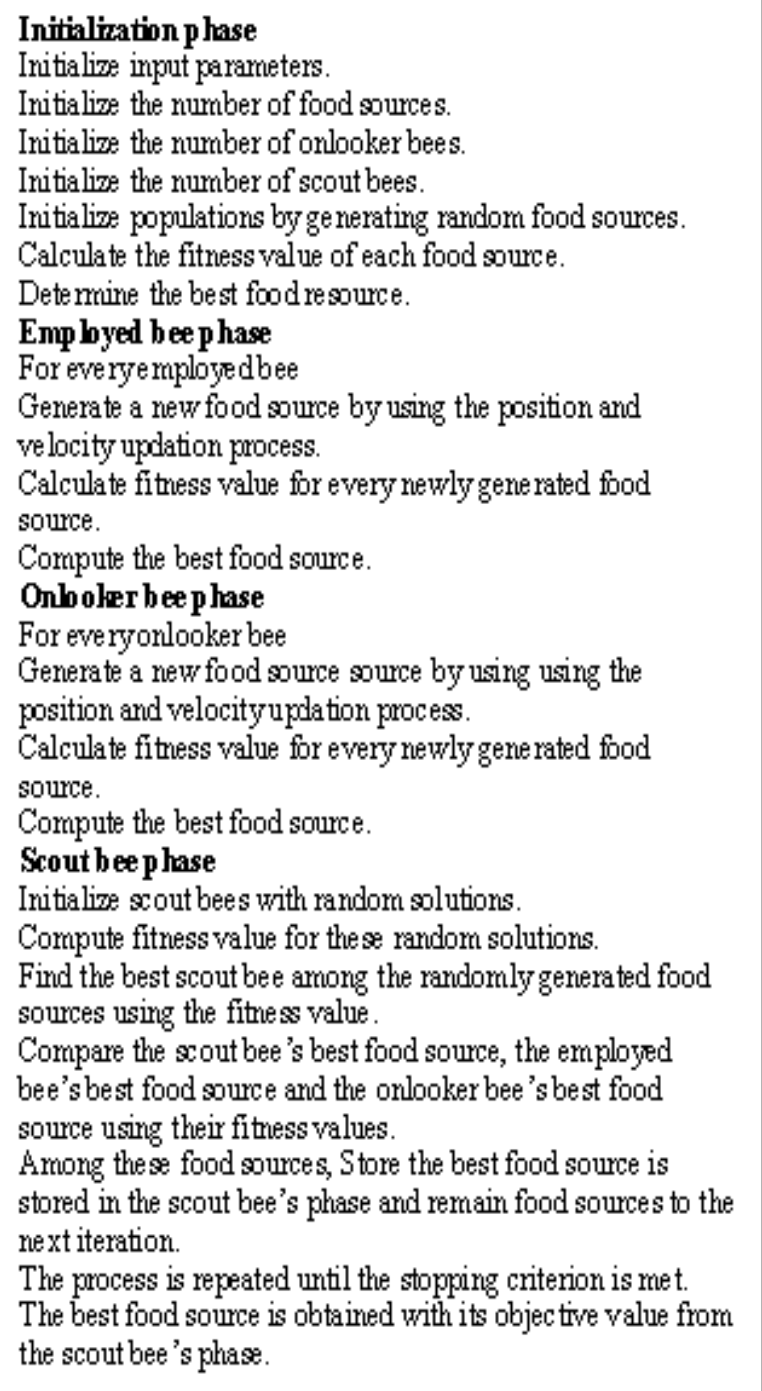

Fig. 1. The Procedure of HABCPSO2.

The fitness function $\mathrm{F}$ minimized in $[\mathrm{PSO}+\mathrm{ABC}](\mathrm{F})$ corresponds to the balanced sum of both objectives functions $\mathrm{F} 1$ and $\mathrm{F} 2$, with weights $\beta 1$ and $\beta 2$ defined by the function 1 .

The fitness functions F1/F2 minimized in $\mathrm{PSO}(\mathrm{F} 1)+\mathrm{ABC}(\mathrm{F} 2)$ corresponds to objective function $\mathrm{F} 1$ minimized in $\mathrm{PSO}(\mathrm{F} 1)$ and objective function $\mathrm{F} 2$ minimized in $\mathrm{ABC}(\mathrm{F} 2)$.

3) Asynchronous parallel hybridization of $A B C$ with PSO: The proposed hybrid method denoted as ABC//PSO is founded on the recombination of two procedures $\mathrm{ABC}$ and PSO, this share and exchange information throughout the search process. The procedures of $\mathrm{ABC} / \mathrm{PSO}$ algorithm are illustrated in Fig. 5.

The fitness function $\mathrm{F}$ minimized in $\mathrm{ABC} / \mathrm{PSO}$ corresponds to the balanced sum of both objectives functions $\mathrm{F} 1$ and $\mathrm{F} 2$, with weights $\beta 1$ and $\beta 2$ defined by the function 1 . 


\section{Initialization p hase}

Initialize input parameters.

Initialize the number of food sources.

Initialize the number of onlooker bees.

Initialize the number of scout bees.

Initialize populations by ge nerating random food sources.

Calculate the fitness value of each food source.

Determine the best food resource.

\section{Emp byed bee phase}

For everye mployed bee

Generate a new food source by using the position and velocity updation proces.

Calculate fitness value for every newly generated food source.

Compute the best food source.

\section{Onboler beephase}

For everyonlooker bee

Generate a new food source source by using using the position and velocity updation process.

Calculate fitness value for every newly generated food source.

Compute the best food source.

\section{Scout bee phase}

For every

Generate a new food source source by using using the position and velocity updation process.

Calculate fitness value for every newly generated food source. Compute the best food source.

Compare the scout bee's best food source, the employed bee's best food source and the onlooker bee's best food source using their fitness values.

Among these food sources, Store the best food source is stored in the scout bee's phase and remain food sources to the next

iteration.

The process is repeated until the stopping criterion is met. The best food source is obtained with its objective value from the scout bee's phase.

Fig. 2. The Procedure of HABCPSO3.

Initialize the population of food sources.

Repeat

Put the employed bees on their food sources in the memory and updating feasible food source

Put the onlooker bees on the food sources depending on their nectar amounts

Transmit the scouts to the search zone in order to discovering new food sources

Memorize the best solution attained

Until stop criterion is met

Initialize the PSO Population

Add the best solution of $\mathrm{ABC}$ to PSO population

Repeat

Calculate fitness values of particles

Modify the best particles in the swarm

Choose the best particle

Calculate the velocities of particles

Update the particle positions

Memorize the best solution attained

Until stop criterion is met

Return the best solution

Fig. 3. The Procedure of $[\mathrm{ABC}+\mathrm{PSO}](\mathrm{F})$ and $\mathrm{ABC}(\mathrm{F} 1)+\mathrm{PSO}(\mathrm{F} 2)$.

Initialize the PSO Population
Repeat
Calculate fitness values of particles
Modify the best particles in the swarm
Choose the best particle
Calculate the velocities of particles
Update the particle positions
Memorize the best solution attained
Until stop criterion is met
Initialize the population of food sources.
Add the best solution of PSO to ABC population
Repeat
Put the employed bees on their food sources in the memory and updating
feasible food source
Put the onlooker bees on the food sources depending on their nectar
amounts
Transmit the scouts to the search zone in order to discovering new food
sources |
Memorize the best solution attained
Until stop criterion is met
Return the best solution

Fig. 4. The Procedure of $[\mathrm{PSO}+\mathrm{ABC}](\mathrm{F})$ and $\mathrm{PSO}(\mathrm{F} 1)+\mathrm{ABC}(\mathrm{F} 2)$.

Initialize the PSO Population
Repeat
Calculate fitness values of particles
Modify the best particles in the swarm
Choose the best particle
Calculate the velocities of particles
Update the particle positions
Put the employed bees (best particles) on their food sources in the memory
and updating feasible food source
Put the onlooker bees on the food sources depending on their nectar
amounts
Transmit the scouts to the search zone in order to discovering new food
sources
Memorize the best solution attained
Until stop criterion is met
Return the best solution

Fig. 5. The Procedure of ABC//PSO.

\section{RESULTS AND DISCUSSION}

Authors are suggested to solve the multi-objective scheduling problem in the automotive company. This company produces automotive parts in different elastomeric materials, including silicone and TPE.

The automotive company workshop is a flow shop contains 17 production lines, each line is composed with seven workstations:

- M1: The injection machine.

- M2: The deburring workstation.

- M3: The inspection workstation.

- M4: The assembly workstation number 1.

- M5: The assembly workstation number 2.

- M6: The color control machine.

- M7: The inspection workstation of the finished product.

The real result of scheduling obtained from the production planner is shown in Table II. 
Several operations of cleaning and tools change or parameter adjustment are managed in the workstations, parallelly with the production operations.

Dates are calculated from an initial time $t 0$, and the time unit is expressed in minute.

The fitness function of total production cost is denoted F1 and the fitness function of the stopping cost and the cost of notuse of the production line are denoted F2.

The fitness function F1 and F2 are given as follows:

$\mathrm{F}_{1}=\mathrm{C}_{\mathrm{prod}}^{\mathrm{tot}}=\sum_{\mathrm{k}} \sum_{\mathrm{i}} \mathrm{W}_{\mathrm{ik}} \mathrm{P}_{\mathrm{ik}} \mathrm{C}_{\mathrm{k}}^{\mathrm{ui}}$

$$
\mathrm{W}_{\mathrm{ik}}=\left\{\begin{array}{c}
1: \text { If the product is maked in the production line } \\
0: \text { Otherwise }
\end{array}\right.
$$

$\mathrm{F}_{2}=\mathrm{C}_{\mathrm{arr}}^{\mathrm{tot}}=\sum_{\mathrm{k}} \mathrm{C}_{\mathrm{arr} \mathrm{k}} \sum_{\mathrm{i}} \mathrm{W}_{\mathrm{ik}} \mathrm{tp}_{\mathrm{ik}}^{\mathrm{arr}}+\mathrm{tp}_{\mathrm{ik}}^{\text {nu }}$ tel que $\mathrm{tp}_{\mathrm{ik}}^{\mathrm{arr}}=$ $\mathrm{D}_{\mathrm{ik}}^{\text {nett }}+\mathrm{D}_{\mathrm{ik}}^{\mathrm{chf}}$,

$W_{\mathrm{ik}}=\left\{\begin{array}{c}1: \text { If the product is maked in the production line } \\ 0: \text { Otherwise }\end{array}\right.$

Consequently, the fitness function $\mathrm{F}$ is given as follows:

$\mathrm{F}=\mathrm{F}_{1} \beta_{1}+\mathrm{F}_{2} \beta_{2}, \beta_{1}+\beta_{2}=1, \beta_{1}>0, \beta_{2}>0$

$F=\beta_{1} C_{\text {prod }}^{\text {tot }}+\beta_{2} C_{\text {arr }}^{\text {tot }}, \beta_{1}+\beta_{2}=1, \beta_{1}>0, \beta_{2}>0$

$\mathrm{F}=\beta_{1}\left(\sum_{\mathrm{k}} \sum_{\mathrm{i}} \mathrm{W}_{\mathrm{ik}} \mathrm{P}_{\mathrm{ik}} \mathrm{C}_{\mathrm{k}}^{\mathrm{ui}}\right)+\beta_{2}\left(\sum_{\mathrm{k}} \mathrm{C}_{\mathrm{arr} \mathrm{k}} \sum_{\mathrm{i}} \mathrm{W}_{\mathrm{ik}} \mathrm{tp}_{\mathrm{ik}}^{\mathrm{arr}}+\right.$

$\left.\operatorname{tp}_{\mathrm{ik}}^{\mathrm{nu}}\right)$,

$\beta_{1}+\beta_{2}=1, \beta_{1}>0, \beta_{2}>0$

The value considered for factors $\beta_{1}$ and $\beta_{2}$ is 0.5 .

- $\mathrm{F}_{\mathrm{ik}}$ : Manufacturing operation of the product $\mathrm{i}$ in the production line $\mathrm{Ch}_{\mathrm{k}}$.

- $\mathrm{P}_{\mathrm{i}}$ : Finished product after the operation $\mathrm{F}_{\mathrm{ik}}$.

- $\mathrm{P}_{\mathrm{ik}}$ : Manufacturing time of the operation $\mathrm{F}_{\mathrm{ik}}$.

- $\mathrm{CP}_{\mathrm{ik}}$ : Time of the end of the execution of $\mathrm{P}_{\mathrm{i}}$ in the production line $\mathrm{Ch}_{\mathrm{k}}$.

- $\mathrm{CP}_{\mathrm{i}}^{\text {stk }}$ : Storage cost by unit of time of the product $\mathrm{P}_{\mathrm{i}}$.

- $t \mathrm{p}_{\mathrm{ik}}$ : Setup time of the production line $\mathrm{Ch}_{\mathrm{k}}$ before the operation $\mathrm{F}_{\mathrm{ik}}$.

- $t \mathrm{tp}_{\mathrm{ik}}^{\mathrm{arr}}$ : Stopping time during the operation $\mathrm{F}_{\mathrm{ik}}$ in the line $\mathrm{Ch}_{\mathrm{k}}$

- $t \mathrm{tp}_{\mathrm{ik}}^{\mathrm{nu}}$ : Time of no use of the line $\mathrm{Ch}_{\mathrm{k}}$ before the operation Fik.

- $\mathrm{C}_{\text {prod }}^{\text {tot }}$ : Total production cost.

- $\mathrm{C}_{\mathrm{k}}^{\mathrm{ui}}$ : The production unit cost of the product $\mathrm{i}$ in the production line $\mathrm{Ch}_{\mathrm{k}}$.
- $\mathrm{D}_{\mathrm{ik}}^{\text {nett }}$ : Operations duration of the cleaning in the production line $\mathrm{Ch}_{\mathrm{k}}$.

- $\mathrm{D}_{\mathrm{ik}}^{\mathrm{chf}}$ : Changes format duration in the production line $\mathrm{Ch}_{\mathrm{k}}$.

- $\mathrm{C}_{\mathrm{arr} \mathrm{k}}$ : Stopping costs and no use of the production line $\mathrm{Ch}_{\mathrm{k}}$ per unit time.

- $\mathrm{C}_{\mathrm{arr}}^{\text {tot }}$ : Total stopping cost and no use of line by time unit.

- trop_Ch$:$ The production time expressed in time unit.

- $\quad \operatorname{tar}{ }_{-} \mathrm{Ch}_{\mathrm{i}}$ : The stopping time expressed in time unit.

- tnett_Ch : The cleaning time expressed in time unit.

- Cpro_Ch${ }_{\mathrm{i}}$ : Production costs.

- Cnou_Ch $\mathrm{Ch}_{\mathrm{i}}$ : The costs of no use of the production line.

In the employed bees phase; the function of updated memory is as follows [22]:

$y_{i j}=x_{i j}+\emptyset_{i j}\left(x_{i j}+x_{k j}\right), k \neq i, \mathrm{i}=\{1,2 \ldots, \mathrm{SN}\}, \mathrm{j}=$

$\{1,2 \ldots, \mathrm{D}\}, \emptyset_{i j}=\operatorname{Rand}[-1,1]$

$\mathrm{x}_{\min }, \mathrm{x}_{\max }$ are respectively the lower bound and the upper bound of the search scope and $\mathrm{y}_{\mathrm{ij}}$ is new feasible dimension value of the food sources that is modified from its previous food sources value $\mathrm{x}_{\mathrm{ij}}$.

In the onlooker bees phase, the probability value related with the food source (pi) is as follows [22]:

$p_{i}=\frac{\text { fit }_{i}}{\sum_{k=1}^{S N} \text { fit }_{k}}$

fit $_{\mathrm{i}}$ is the fitness value of the solution.

In the scout bees phase, the transmission function is defined as follows [21]:

$x_{i}^{j}=x_{\min }^{j}+\operatorname{rand}[0,1]\left(x_{\max }^{j}-x_{\min }^{j}\right)$

Each iteration a particle's velocity and a particle's position are updated according to the equation:

$\mathrm{Vk}+1=\mu \mathrm{V}[\mathrm{k}]+\mathrm{C} 1 * \operatorname{rand}()^{*}(\operatorname{pbest}[\mathrm{k}]$-current $[\mathrm{k}])+\mathrm{C} 2 * \operatorname{rand}()$

* (gbest[k]-current[k]), C1 + C2 = 1

$\mu$ is the inertia factor and used to control intensification and diversification, $\mathrm{V}[]$ is the particle velocity and $\mathrm{C} 1 / \mathrm{C} 2$ are the apprenticeship factors.

The algorithms were programmed in Java and executed in Core ${ }^{\text {TM }}$ i7 CPU with $2.5 \mathrm{GHz}$ and 8 Go de RAM.

The ABC stopping criterion defines the maximum number of cycles that a food source can keep without improvement.

The tarr_ $\mathrm{Ch}_{\mathrm{i}}$ and tnett_ $\mathrm{Ch}_{\mathrm{i}}$ values of product $\mathrm{i}$ in each production line are given as follows:

$\forall \mathrm{i}=\{1,2,3, \ldots, 17\} \quad \operatorname{tarr}_{-} \mathrm{Ch}_{\mathrm{i}}\left(\mathrm{P}_{\mathrm{i}}\right) \in[5,10]$

$\forall \mathrm{i}=\{1,2,3, \ldots, 17\} \quad$ tnett_ $\mathrm{Ch}_{i}\left(\mathrm{P}_{\mathrm{i}}\right) \in[5,15]$

The trop_ $\mathrm{Ch}_{\mathrm{i}}$ value of product $\mathrm{i}$ in each production line is given as follows: 
TABLE II. The Global Results of the Proposed Methods AND THE REAL Results

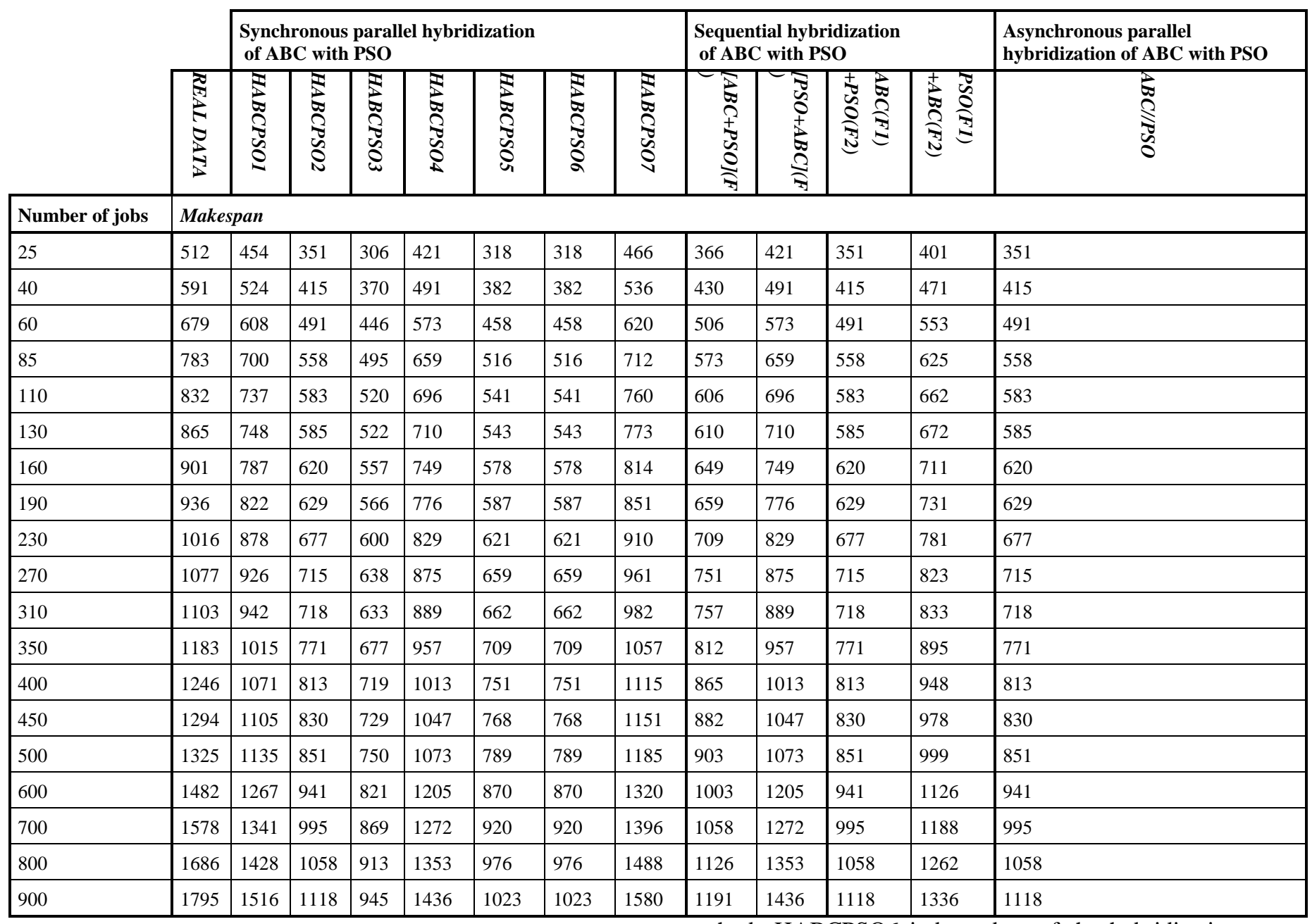

$\forall \mathrm{i}=\{1,2,3, \ldots, 17\} \quad$ trop_Ch $\mathrm{Ch}_{\mathrm{i}}\left(\mathrm{P}_{\mathrm{i}}\right) \in[30,90]$

The Cpro_Ch $\mathrm{h}_{\mathrm{i}}$ and $\mathrm{Cnou}_{-} \mathrm{Ch}_{\mathrm{i}}$ values of product $\mathrm{i}$ in each production line are calculated according to formulas 2 and 3 and fitness function deducted from formulas 4 and 5.

The global results of the proposed methods are shown in Table II.

The computational results demonstrate that all proposed methods are given the best results compared with the real results in terms of solution quality.

The results show that the synchronous parallel hybridization method HABCPSO3 is given the best results compared with other results obtained by the sequential hybridization methods and the asynchronous parallel hybridization methods.

The results show that the synchronous parallel hybridization method HABCPSO3 is given the best results compared with other results obtained by the synchronous parallel hybridization methods, the synchronous parallel hybridization method HABCPSO5 is given the equal results to the results obtained by the synchronous parallel hybridization methods HABCPSO6 independent of the hybridization type. These are presented in Fig. 6.

The ranking of the synchronous parallel hybridization methods in terms of performance according to the hybridization type is shown in Table III.

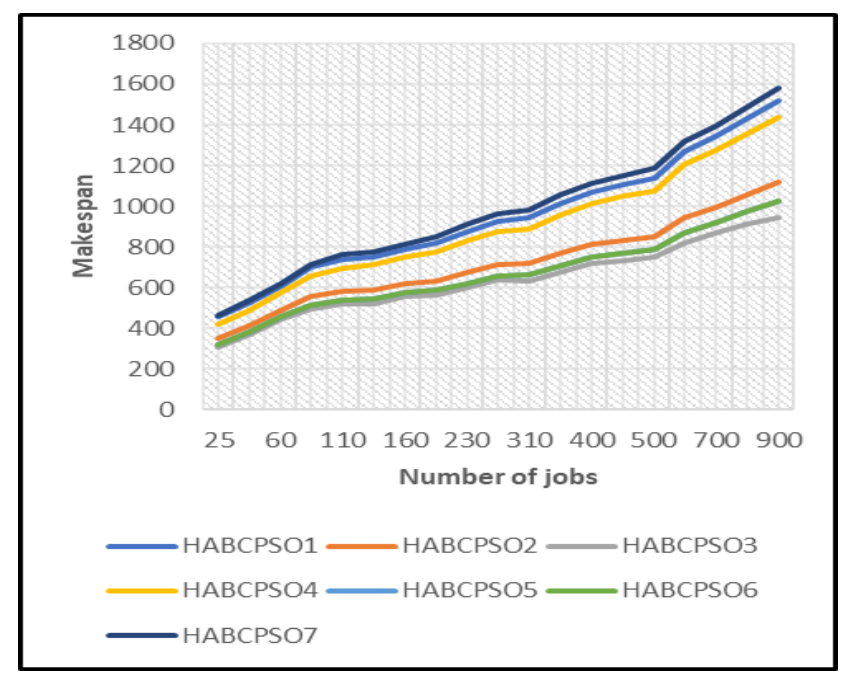

Fig. 6. The Results of the Synchronous Parallel Hybridization Methods. 
TABLE III. THE RANKING OF THE SYNCHRONOUS PARALLEL HYBRIDIZATION METHODS

\begin{tabular}{|l|l|l|l|l|}
\hline \multirow{2}{*}{$\begin{array}{l}\text { Ranki } \\
\text { ng }\end{array}$} & \multicolumn{3}{|l|}{ Synchronous parallel hybridization of ABC and PSO } \\
\cline { 2 - 5 } & $\begin{array}{l}\text { HABCPS } \\
\text { OX }\end{array}$ & $\begin{array}{l}\text { Employed bees } \\
\text { phase }\end{array}$ & $\begin{array}{l}\text { Onlooker bees } \\
\text { phase }\end{array}$ & $\begin{array}{l}\text { Scout bees } \\
\text { phase }\end{array}$ \\
\hline 5 & $\begin{array}{l}\text { HABCPS } \\
\text { O1 }\end{array}$ & PSO & & \\
\hline 3 & $\begin{array}{l}\text { HABCPS } \\
\text { O2 }\end{array}$ & PSO & PSO & PSO \\
\hline 1 & $\begin{array}{l}\text { HABCPS } \\
\text { O3 }\end{array}$ & PSO & PSO & PSO \\
\hline 4 & $\begin{array}{l}\text { HABCPS } \\
\text { O4 }\end{array}$ & & PSO & PSO \\
\hline 2 & $\begin{array}{l}\text { HABCPS } \\
\text { O5 }\end{array}$ & & PSO & PSO \\
\hline 2 & $\begin{array}{l}\text { HABCPS } \\
\text { O6 }\end{array}$ & PSO & & \\
\hline 6 & HABCPS & & & \\
\hline
\end{tabular}

Fig. 7 is shown that the sequential hybridization method $\mathrm{ABC}(\mathrm{F} 1)+\mathrm{PSO}(\mathrm{F} 2)$ is given the best results compared with other results obtained by the other sequential hybridization methods.

As shown in Fig. 7:

- The sequential hybridization method $[\mathrm{ABC}+\mathrm{PSO}](\mathrm{F})$ is given the best results compared with the results obtained by the sequential hybridization method $[\mathrm{PSO}+\mathrm{ABC}](\mathrm{F})$.

- The sequential hybridization method $\mathrm{ABC}(\mathrm{F} 1)+\mathrm{PSO}(\mathrm{F} 2)$ is given the best results compared with the results obtained by the sequential hybridization method $\mathrm{PSO}(\mathrm{F} 1)+\mathrm{ABC}(\mathrm{F} 2)$.

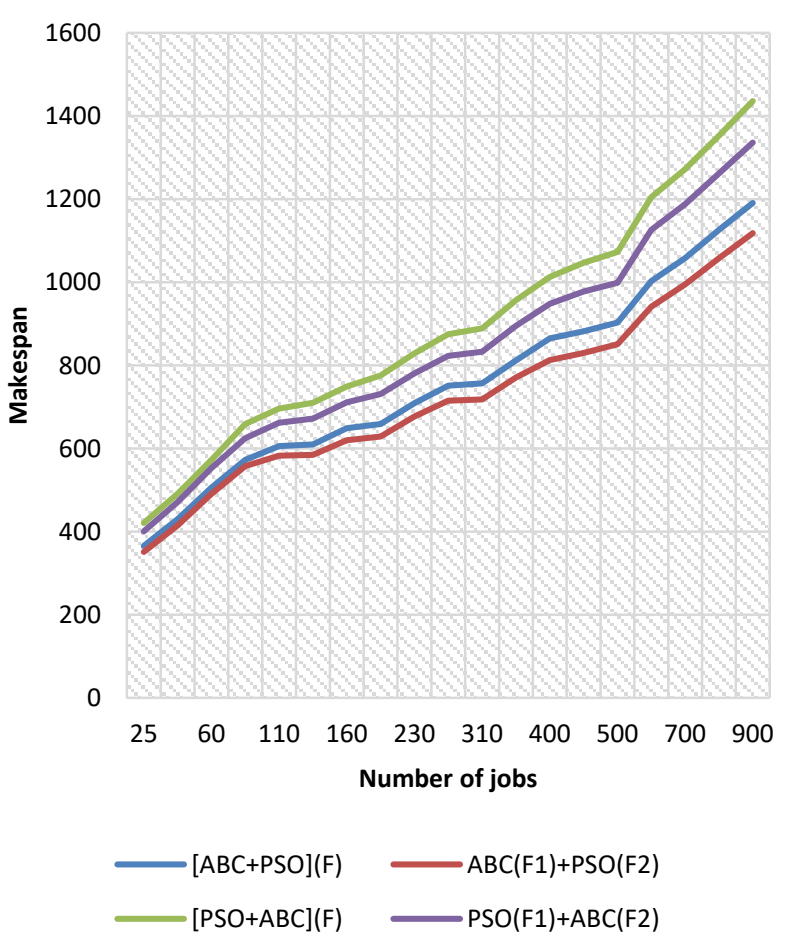

Fig. 7. The Results of the Sequential Hybridization Methods.
TABLE IV. THE RANKING OF THE SEQUENTIAL HybRIDIZATION METHODS

\begin{tabular}{|l|l|}
\hline Ranking & Sequential hybridization of $\mathrm{ABC}$ and PSO \\
\hline 1 & $\mathrm{ABC}(\mathrm{F} 1)+\mathrm{PSO}(\mathrm{F} 2)$ \\
\hline 2 & {$[\mathrm{ABC}+\mathrm{PSO}](\mathrm{F})$} \\
\hline 3 & $\mathrm{PSO}(\mathrm{F} 1)+\mathrm{ABC}(\mathrm{F} 2)$ \\
\hline 4 & {$[\mathrm{PSO}+\mathrm{ABC}](\mathrm{F})$} \\
\hline
\end{tabular}

The ranking of the sequential hybridization methods in terms of performance according to the fitness function F or F1 and F2 is shown in Table IV.

The results show that the asynchronous parallel hybridization method $\mathrm{ABC} / \mathrm{PSO}$ is given the equal results to the results obtained by the sequential hybridization method $\mathrm{ABC}(\mathrm{F} 1)+\mathrm{PSO}(\mathrm{F} 2)$, the asynchronous parallel hybridization method $\mathrm{ABC} / / \mathrm{PSO}$ is given the best results compared with other results obtained by the other sequential hybridization methods $[\mathrm{ABC}+\mathrm{PSO}](\mathrm{F}), \mathrm{PSO}(\mathrm{F} 1)+\mathrm{ABC}(\mathrm{F} 2), \quad[\mathrm{PSO}+\mathrm{ABC}]$ (F).

The ranking of the asynchronous parallel hybridization method and the sequential hybridization methods in terms of performance according to the fitness function F or F1 and F2 is shown in Table V.

As shown in Fig. 8:

- The synchronous parallel hybridization method HABCPSO2 is given the equal results to the results obtained by the sequential hybridization method $\mathrm{ABC}(\mathrm{F} 1)+\mathrm{PSO}(\mathrm{F} 2)$ and the asynchronous parallel hybridization method $\mathrm{ABC} / \mathrm{PSO}$.

- The synchronous parallel hybridization HABCPSO4 is given the equal results to the results obtained by the Sequential hybridization $[\mathrm{PSO}+\mathrm{ABC}](\mathrm{F})$.

- The synchronous parallel hybridization method HABCPSO2, the sequential hybridization method $\mathrm{ABC}(\mathrm{F} 1)+\mathrm{PSO}(\mathrm{F} 2)$ and the asynchronous parallel hybridization method $\mathrm{ABC} / \mathrm{PSO}$ are given the best results compared with other results obtained by the synchronous parallel hybridization HABCPSO 4 and the sequential hybridization $[\mathrm{PSO}+\mathrm{ABC}](\mathrm{F})$.

- The synchronous hybridization method $\mathrm{ABC}(\mathrm{F} 1)+\mathrm{PSO}(\mathrm{F} 2)$ is given the best results compared with other results obtained by the synchronous hybridization method [PSO+ABC](F).

TABLE V. THE RANKING OF THE ASYNCHRONOUS PARALLEL HYBRIDIZATION METHOD AND THE SEQUENTIAL HYBRIDIZATION METHODS

\begin{tabular}{|c|c|c|}
\hline $\begin{array}{l}\text { Rankin } \\
\text { g }\end{array}$ & \multicolumn{2}{|l|}{ Hybrid ABC and PSO } \\
\hline 1 & $\begin{array}{l}\text { Asynchronous parallel hybridization } \\
\text { of ABC and PSO }\end{array}$ & $\mathrm{ABC} / / \mathrm{PSO}$ \\
\hline 1 & \multirow{4}{*}{$\begin{array}{l}\text { Sequential hybridization of } \mathrm{ABC} \text { and } \\
\text { PSO }\end{array}$} & $\mathrm{ABC}(\mathrm{F} 1)+\mathrm{PSO}(\mathrm{F} 2)$ \\
\hline 2 & & {$[\mathrm{ABC}+\mathrm{PSO}](\mathrm{F})$} \\
\hline 3 & & $\mathrm{PSO}(\mathrm{F} 1)+\mathrm{ABC}(\mathrm{F} 2)$ \\
\hline 4 & & {$[\mathrm{PSO}+\mathrm{ABC}](\mathrm{F})$} \\
\hline
\end{tabular}




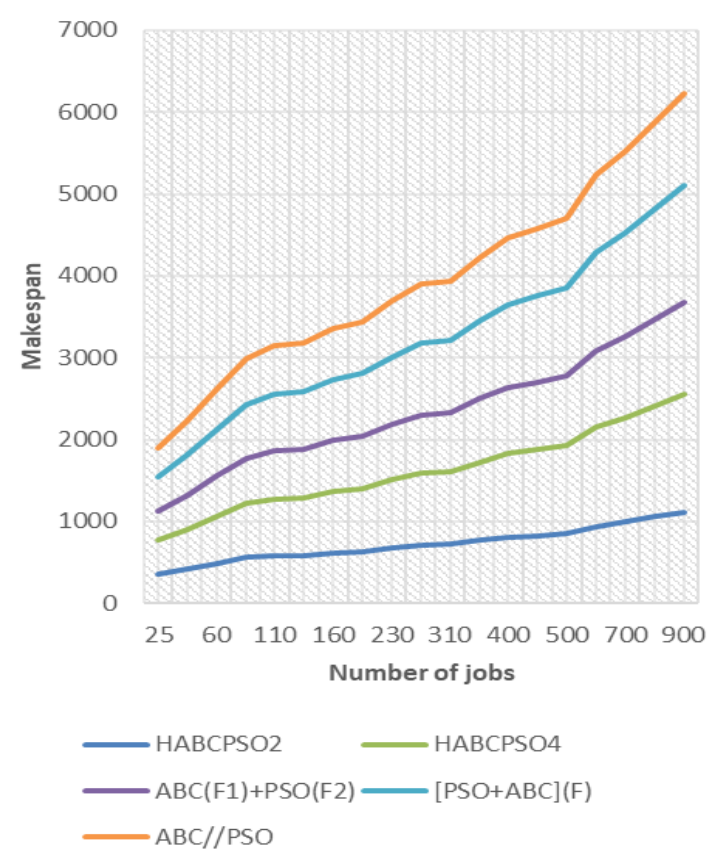

Fig. 8. The Results of the Synchronous Parallel Hybridization Methods HABCPSO2 / HABCPSO4 and the Asynchronous Parallel Hybridization Method $\mathrm{ABC} / \mathrm{PSO}$ and the Sequential Hybridization Methods $\mathrm{ABC}(\mathrm{F} 1)+\mathrm{PSO}(\mathrm{F} 2) /[\mathrm{PSO}+\mathrm{ABC}](\mathrm{F})$.

The ranking of the synchronous parallel hybridization methods HABCPSO2 / HABCPSO4 and the asynchronous parallel hybridization method $\mathrm{ABC} / \mathrm{PSO}$ and the sequential hybridization methods $\mathrm{ABC}(\mathrm{F} 1)+\mathrm{PSO}(\mathrm{F} 2) /[\mathrm{PSO}+\mathrm{ABC}](\mathrm{F})$ in terms of performance according to the fitness function is shown in Table VI.

The ranking of all proposed methods in terms of performance according to the fitness function F or F1 and F2 is shown in Table VII.

Summing up the results according to the ranking of the proposed methods in terms of performance, it can be concluded that:

- The proposed methods are given the best results compared with the real results of scheduling.

- The synchronous parallel hybridization of $\mathrm{ABC}$ in its three phases using the fitness function $\mathrm{F}$ is produced the best result.

- The synchronous parallel hybridization of $\mathrm{ABC}$ in its two phases (onlooker bees phase and scout bees phase) using the fitness function $\mathrm{F}$ is produced the equal results to the results of the synchronous parallel hybridization of $\mathrm{ABC}$ in its two phases (employed bees phase and scout bees phase) using the weighted sum method of the fitness function $\mathrm{F}$.

- The synchronous parallel hybridization of ABC in its two phases using the weighted sum method of the fitness function $\mathrm{F}$ (employed bees phase and onlooker bees phase) is given $100 \%$ results equal to the results of the sequential hybridization of ABC with PSO using the weighted sum method of the fitness function $F$ and equal to the results of the asynchronous parallel hybridization of ABC with PSO using the weighted sum method of the fitness function $\mathrm{F}$.

- The sequential hybridization of ABC with PSO using the weighted sum method of the fitness function $F$ is given the better results than the sequential hybridization of PSO with ABC using the fitness functions F1 and F2.

- The synchronous parallel hybridization $\mathrm{ABC}$ in its onlooker bees phase using the weighted sum method of the fitness function $\mathrm{F}$ is produced the equal results to the results of the sequential hybridization of $\mathrm{ABC}$ with PSO using two fitness functions F1 and F2.

- The synchronous parallel hybridization of ABC in its employed bees phase using the weighted sum method of the fitness function $\mathrm{F}$ is produced the better result than the synchronous parallel hybridization of $\mathrm{ABC}$ in its scout bees phase using the weighted sum method of the fitness function $\mathrm{F}$.

The authors' attention was concentrated not only on develops these three hybridization categories of the evolutionary methods $\mathrm{ABC}$ and PSO but also on tests of these hybrid methods in an automotive multi-objective flow shop and on their performance evaluation to make a perform comparison. The main limitation of the experimental that it is take into account the fitness function $\mathrm{F} 1 / \mathrm{F} 2$ only in the sequential hybridization of $\mathrm{ABC}$ and PSO.

TABLE VI. THE SYNCHRONOUS PARALLEL HYBRIDIZATION METHODS HABCPSO2 / HABCPSO4 AND THE ASYNCHRONOUS PARALLEL HYBRIDIZATION METHOD ABC//PSO AND THE SEQUENTIAL HYBRIDIZATION Methods ABC(F1)+PSO(F2) / [PSO+ABC](F)

\begin{tabular}{|c|c|c|}
\hline $\begin{array}{l}\text { Rankin } \\
\text { g }\end{array}$ & \multicolumn{2}{|l|}{ Hybrid ABC and PSO } \\
\hline 1 & $\begin{array}{l}\text { Asynchronous parallel hybridization of } \mathrm{ABC} \\
\text { and PSO }\end{array}$ & $\mathrm{ABC} / / \mathrm{PSO}$ \\
\hline 1 & \multirow{2}{*}{ Sequential hybridization of $\mathrm{ABC}$ and PSO } & $\begin{array}{l}\mathrm{ABC}(\mathrm{F} 1)+\mathrm{PSO}( \\
\mathrm{F} 2)\end{array}$ \\
\hline 2 & & {$[\mathrm{PSO}+\mathrm{ABC}](\mathrm{F})$} \\
\hline 1 & \multirow{2}{*}{$\begin{array}{l}\text { Synchronous parallel hybridization of } \mathrm{ABC} \text { and } \\
\text { PSO }\end{array}$} & HABCPSO2 \\
\hline 2 & & HABCPSO4 \\
\hline
\end{tabular}


TABlE VII. The Ranking of All Proposed Methods in Terms of Performance

\begin{tabular}{|c|c|c|c|c|c|c|c|}
\hline Ranking & \multicolumn{2}{|l|}{ Hybrid ABC and PSO } & $\begin{array}{l}\text { Employed } \\
\text { bees } \\
\text { phase }\end{array}$ & $\begin{array}{l}\text { Onlooker } \\
\text { bees } \\
\text { phase }\end{array}$ & $\begin{array}{l}\text { Scout } \\
\text { bees } \\
\text { phase }\end{array}$ & $\begin{array}{l}\text { Hybridation } \\
\text { number }\end{array}$ & $\begin{array}{l}\text { Fitness } \\
\text { function }\end{array}$ \\
\hline 1 & Synchronous parallel hybridization of ABC and PSO & HABCPSO3 & PSO & PSO & PSO & 3 & $\mathrm{~F}$ \\
\hline 2 & Synchronous parallel hybridization of ABC and PSO & HABCPSO6 & PSO & & PSO & 2 & $\mathrm{~F}$ \\
\hline 3 & Synchronous parallel hybridization of ABC and PSO & HABCPSO2 & PSO & PSO & & 2 & $\mathrm{~F}$ \\
\hline 3 & Asynchronous parallel hybridization of $\mathrm{ABC}$ and PSO & $\mathrm{ABC} / / \mathrm{PSO}$ & & & & 1 & $\mathrm{~F}$ \\
\hline 4 & Sequential hybridization of $\mathrm{ABC}$ and $\mathrm{PSO}$ & {$[\mathrm{ABC}+\mathrm{PSO}](\mathrm{F})$} & & & & 1 & $\mathrm{~F}$ \\
\hline 5 & Sequential hybridization of $\mathrm{ABC}$ and $\mathrm{PSO}$ & $\mathrm{PSO}(\mathrm{F} 1)+\mathrm{ABC}(\mathrm{F} 2)$ & & & & 1 & $\mathrm{~F} 1$ and $\mathrm{F} 2$ \\
\hline 6 & Synchronous parallel hybridization of ABC and PSO & HABCPSO4 & & PSO & & 1 & $\mathrm{~F}$ \\
\hline
\end{tabular}

\section{CONCLUSION}

Powerful methods to solve the multi-objective flow shop scheduling problem are required, due to high level of its complexity.

An adequate hybridization of multiple algorithmic concepts is the key to accomplishing top performance in solving scheduling problems.

Based on the overall experimental results, it can be decided that the proposed methods were capable to solve multiobjective flow shop scheduling problem successfully, efficiently, and robustly in terms of solution quality.

The paper presents a pilot study for verifying how the multi hybridization and the hybridization categories influence the resolution of multi-objective flow shop scheduling problems.

The proposed methods have great potential for other applications such as multi-objective job shop scheduling problem resolution and multi-objective open-shop scheduling problem resolution.

As a future research, we intend to apply the ideas presented in this paper to other scheduling problems such as multiobjective job shop scheduling problem and multi-objective open-shop scheduling problem using other hybrid methods in three hybridization categories.

\section{REFERENCES}

[1] E.G. Talbi, "A taxonomy of hybrid metaheuristics," International Journal of Heuristics, vol. 8, No. 5, pp. 541-564, 2002.

[2] D. Duvidier, "Etude de l'hybridation des méta-heuristiques, application à un problème d'ordonnancement de type jobshop," These de Doctorat, Université du littoral France, France, Déc, 2000.

[3] J.E.C. Arroyo and V.A. Armentano, "Genetic local search for multiobjective flowshop scheduling problems," European Journal of Operational Research, vol. 167, No.3, pp. 717-738, 2005.

[4] A. Noorul Haq and T. Radha Ramanan, "A bicriterian flow shops scheduling using artificial neural network," The International Journal of Advanced Manufacturing Technology, vol. 30, No. 11-12, 2006.
[5] R. Rahimi-Vahed and S.M. Mirghorbani, "A multi-objective particle swarm for a flow shop scheduling problem," Journal of Combinatorial Optimization, vol. 13, No. 1, pp. 79-102, 2007.

[6] J.E.C. Arroyo and A.A. De Souza Pereira, "A GRASP heuristic for the multi-objective permutation flowshop scheduling problem," The International Journal of Advanced Manufacturing Technology, vol. 55, No. 5-8, pp. 741-753, 2010.

[7] J. Dubois-Lacoste, M. López-Ibáñez and T. Stützle, "A hybrid TP+PLS algorithm for bi-objective flow-shop scheduling problems," Computers \& Operations Research, vol. 38, No. 8, pp. 1219-1236, 2011.

[8] M. Ciavotta, G. Minella and R. Ruiz, "Multi-objective sequence dependent setup times permutation flowshop: A new algorithm and a comprehensive study," European Journal of Operational Research, vol. 227, No. 2, pp. 301-313, 2013.

[9] Y. Collette and P. Siarry, "Optimisation Multiobjectif. Editions Eyrolles," Paris, 2002.

[10] Y. Sun, Ch. Zhang, L. Gao, and X. Wang, "Multi-objective optimization algorithms for flow shop scheduling problem: a review and prospects," International Journal of Advanced Manufactoring Technology, DOI 10.1007/s00170-010-3094-4, 2010.

[11] T. Loukil, J. Teghem and D. Tuyttens, "Solving multi-objective production scheduling problems using metaheuristics," European Journal of Operational Research, vol. 161, No. 1, pp. 42-61, 2005.

[12] M. FADAEI, and M. ZANDIEH, "Scheduling a bi-objective hybrid flow shop with sequence-dependent family setup times using metaheuristics," Arabian Journal of Science Engineering, vol. 38, No. 8, pp. 2233-2244, 2013.

[13] F. Dugardin, F. Yalaoui, and L. Amodeo, "New multi-objective method to solve reentrant hybrid flow shop scheduling problem," European Journal of Operational Research, vol. 203, No. 1, pp. 22-31, DOI:10.1016/j.ejor.2009.06.031, 2010.

[14] B. Yagmahan and M.M. Yenisey, "A multi-objective ant colony system algorithm for flow shop scheduling problem," Expert Systems with Applications, vol. 37, No. 2, pp. 1361-1368, 2010.

[15] T.M. Zheng, M. and Yamashiro, "Solving flow shop scheduling problems by quantum differential evolutionary algorithm," The International Journal of Advanced Manufacturing Technology, vol. 49, No. 5-8, pp. 643-662, 2010.

[16] J.R. Figueira, A. Liefooghe, E.G. Talbi and A.P. Wierzbicki, "A parallel multiple reference point approach for multi-objective optimization," European Journal of Operational Research, vol. 205, No. 2, pp. 390-400, 2010.

[17] J. Senthilnath, S.N. Omkar, V. Mani, N. Tejovanth, P.G. Diwakar and S.B. Archana, "Multi-spectral satellite image classification using 
glowworm swarm optimization," In IEEE International Geoscience and Remote Sensing Symposium (IGARSS), pp. 47-50, 2011.

[18] P. Muni Babu, B.V. Himasekhar Sai and A. Sreenivasulu Reddy, "Optimization of make-span and total tardiness for flow-shop scheduling using genetic algorithm," International Journal of Engineering Research and General Science, Vol. 3, Issue. 3, pp. 195-199, 2015.

[19] G. Mohammadi, "Multi-Objective flow shop production scheduling via robust genetic algorithm optimization technique," International Journal of Service Science, Management and Engineering, vol. 2, No. 1, pp. 1-8, 2015.

[20] X. Wang and L. Tang, "A machine-learning based memetic algorithm for the multi-objective permutation flowshop scheduling problem," Computers \& Operations Research, vol. 79, Issue. C, pp. 60-77, 2017.

[21] X. Wu, X. Shen and Q. Cui, "Multi-Objective Flexible Flow Shop Scheduling Problem Considering Variable Processing Time due to Renewable Energy," Sustainability, vol. 10, No. 3, pp. 841, 2018.

[22] Y. Li, X. Li, and J.N. Gupta, "Solving the multi-objective flowline manufacturing cell scheduling problem by hybrid harmony search," Expert Systems with Applications, vol. 42, No. 3, pp. 1409-1417,2015.

[23] V. Arasanipalai Raghavan, S.W. Yoon and K. Srihari, "Heuristic algorithms to minimize total weighted tardiness with stochastic rework and reprocessing times," Journal of Manufacturing Systems, vol. 37, pp. 233-242, DOI:10.1016/j.jmsy.2014.09.004, 2015.

[24] A.J. Yu and J. Seif, "Minimizing tardiness and maintenance costs in flow shop scheduling by a lower-bound-based GA," Computers \& Industrial Engineering, vol. 97, pp. 26-40. DOI:10.1016/j.cie.2016.03.024, 2016.

[25] T. El-Ghazali, F. Yalaoui and L. Amodeo, "Metaheuristics for Production Systems 2015," Springer 2015-11-26.

[26] D. Karaboga and B. Basturk, "A powerful and efficient algorithm for numerical function optimization: artificial bee colony (ABC) algorithm," Journal of Global Optimization, vol. 39, No. 3, pp. 459-471, 2007.
[27] T.M. PanQ-K, P, Suganthan and T. Chua, "A discrete artificial bee colony algorithm for the lot-streaming flow shop scheduling problem," Inf Sci 181, pp. 2455-2468, 2011.

[28] A. Singh, "An artificial bee colony algorithm for the leafconstrained minimum spanning tree problem," Appl Soft Comput 9, pp. 625-631, 2009.

[29] S, Sundar and A. Singh, "A swarm intelligence approach to the quadratic multiple knapsack problem," In: ICONIP 2010. Lecture notes in computer science, vol 6443. Springer, Berlin, pp. 626-633, 2010.

[30] T.M. Pan Q-K, P, Suganthan and AH-L. Chen, "A discrete artificial bee colony algorithm for the total flowtime minimization in permutation flow shops," Inf Sci 181, pp. 3459-3475, 2011.

[31] H. Jebari, S.R. Elazzouzi, H. Samadi and S. Rekiek, "The search of balance between diversification and intensification in artificial bee colony to solve job shop scheduling problem," Journal of Theoretical and Applied Information Technology, vol. 97, No. 2, pp. 658-673, 2019.

[32] D. Karaboga, B. Gorkemli, C. Ozturk and N. Karaboga, "A comprehensive survey: artificial bee colony (abc) algorithm and applications," Artif Intell Rev 42(1), pp. 21-57, 2014.

[33] M. Pontani and B.A. Conway, "Particle Swarm optimization applied to impulsive orbital transfers," Acta Astronautica 74, pp. 141-155, May 2012.

[34] R. Poli, "Analysis of the publications on the applications of particle swarm optimization," Journal of Artificial Evolution and Applications, pp. 1-10, 2008.

[35] K. Vaisakh, L.R. Srinivas and K. Meah, "Genetic evolving ant direction particle swarm optimization algorithm for optimal power flow with nonsmooth cost functions and statistical analysis," Appl. Soft Comput. 13(12), pp. 4579-4593, December 2013.

[36] H. Jebari, S.R. Elazzouzi, H. Samadi and S. Rekiek, "Multi hybridization of swarm intelligence methods to solve job shop scheduling problem," Journal of Theoretical and Applied Information Technology, vol. 97, No. 16, pp. 4366-4386, 2019. 